\title{
Cancellation of delayed trains: passengers' and capacity points of view
}

\author{
Josef Bulíček ${ }^{1, *}$ \\ ${ }^{1}$ University of Pardubice, Faculty of Transport Engineering, Department of Transport Technology and Control, Studentská 95,53210 \\ Pardubice, Czech Republic
}

\begin{abstract}
The paper is focused on interface between passenger transport demand after utilization of individual trains influenced by current operational situation (delays, overtaking of trains etc.) and on aspects of capacity utilization of railway line. The research is inspired by an idea (based on UIC 406) to operate rush lines on higher level of capacity utilization due to possibility to cancel delayed trains and make the time schedule more stable in this way. Simulation model of distribution of passengers between trains according to current operational situation is modified and applied for this assessment. The main result is that the effectiveness of this measure (especially in passengers' point of view) is depended not only on high capacity utilization of railway line, but also on time schedule and a complex of other operational conditions.
\end{abstract}

\section{Introduction}

This paper refers about the results of preliminary research works realized in the field of railway infrastructure capacity within the project PosiTrans solved at the University of Pardubice.

There is a tendency to shorten headway times between trains on railway especially in suburban areas. Effort to create railway more attractive for passengers can be a reason. The aim is to create transport system with similar features like in urban public transport. Short headway times belong to these features. Capacity utilization of railway infrastructure is increased due to this tendency.

The impact of possible delay can be a question in the case of shortened headway times. Possible delay can cause redistribution of passengers between individual trains in this case, so that the demand after delayed train can be seriously reduced. This leads to an idea to cancel such delayed trains [1]. Train cancellation can be helpful for operational stability and can be used as a tool allowing designing of time schedules with higher capacity utilization (occupancy rate) than in the case when redistribution of passengers' demand and related train cancellation are not possible. This can be description of an invited effect. The interface between passengers' point of view and capacity is researched as a scope of this paper. For some cases. This possibility is also considered by and based on the UIC 406 Codex Capacity [1] for estimation of capacity of railway transport infrastructure.

Simulation model designed for exploitation of train passenger capacity, taking into account potential delays, is applied. This model was developed by the Department of Transport Technology and Control at the Faculty of
Transport Engineering of the University of Pardubice. [2] Simulation in field of railway capacity estimation is also international accepted approach, e.g. [3]. Consideration of robustness within planning of railway operation is accented by [4] and [5]. Interconnection of quality, capacity, dispatching and performance is creating a scope of the research presented in [6]. As follows from this brief analysis, this theme is topical on international scientific level at present time.

Potential delay of individual trains can lead to a change of demand with passengers moving to another train. Problem is that this effect can be occurred with no regard if delayed train is operated or cancelled. In some cases, passenger capacity might be insufficient, while in other cases it can be unexploited. This effect is the focus of the model as well.

In terms of the approach to transport demand, the model can be classified as a microscopic simulation model. As for the approach to traffic, macroscopic modelling is usually sufficient. Overall, the model can thus be classified as mesoscopic.

Simulation models are generally descriptive. It follows that naturally, the quality of outputs depends on the quality of inputs, specific set of realized replications and the scope of simulation experiments (replications) carried out. [7]

It is also to be noted that the aim of this paper is to present the situation on a methodological and general level. That's why the individual inputs and outputs of the model are characterized by their type and description of their processing, rather than by specific values. The specific values need to be established on a case-by-case basis, as there can be differences in practice. These differences can exist on all levels - in the way the

\footnotetext{
Corresponding author: josef.bulicek@upce.cz
} 
passengers accumulate, in their decision making regarding the train they would use, and in the railway transport organisation itself (e.g. different priorities in waiting for delayed connecting trains).

The aim of this paper is to identify in which cases is possibly relevant to cancel the trains and which effects influencing this. This will be done next to brief model presentation and although the fact that model results have particular character as it was mentioned above.

\section{Problem definition}

As indicated above, the model focuses on the changes of use of train passenger capacity considering a potential delay and mutual "interaction" of different trains within a common section or in a part of railway network serving the same transport relation.

In case of a delay, the passenger generally:

a) waits for the train he/she intended to use (even though he could use another (replacement) train),

b) uses a delayed train he didn't intend to use, using which he/she expects to reach the final destination (or interchange station) earlier, as he/she came to the station earlier and caught the delayed train unexpectedly,

c) uses a replacement train where the (delayed) train he/she intended to use hasn't arrived until the departure of the replacement train, using which he/she expects to reach the final destination earlier.

On the other hand, the reaction of individual passengers to a train delay is often ambiguous. The reasons why different passengers wouldn't react in the same way can be the following:

a) the delay length, number and structure of the respective trains,

b) possibilities to reach the final station (including the available information on trains),

c) ticket validity (e.g. different rates for different trains, inclusion of the train in the integrated transport system, obligatory seat reservation, etc.),

d) wheelchair accessibility of the train,

e) other factors - e.g. the possibilities of transport of baggage, bicycles, prams, or direct connection requirements.

These factors often don't apply absolutely and it is more or less possible that in the end, the passenger decides differently than expected. For instance the passenger can give up a reserved seat and use a replacement train. In other cases, he/she can reserve a seat for a train with obligatory seat reservation. This means that the model cannot provide a clear solution to this, but it needs to consider the aspect of "willingness" to these decisions, e.g. to consider their probability.

The purpose of the proposed model is to monitor passengers' demand for a given train collection, including the changes to this demand caused by the effect of potential delays, so that these changes can be predicted and considered in establishing the passenger capacity (number and type of cars, or units) for individual trains.
To meet the above mentioned purposes, it is necessary to create a microscopic model to be able to distinguish between different batches of passengers. This approach is also advantageous if trains with minimum use are included. The principle is basically the same as for the discrete model of transport demand, as presented in [8].

On the other hand, even entering such a large scope of input data can be problematic. For the above mentioned reasons, it is necessary to create support processes to potentially replace this data entering and to function based on the assumed general characteristics. This ultimately means that even the basic input establishing the transport demand - will be subject to modelling, including the deliberate simplification and generalization. For instance, accumulation of passengers is modelled in uniform manner in model application presented in chapter 8 of this paper.

The structure of the model is modular, meaning that the processes (approaches) involved both in input data entering, and evaluation, can be complemented, combined and used simultaneously or alternatively depending on the given situation. Consideration can be equipped by other methods for capacity estimation, mentioned e.g. in [9].

Specific functions and procedures were added and applied into the model also within the research of train cancellation. Number of trains with decreased transport demand can be evaluated in relation to general indicators reflecting transport situation like average delay, ratio of delayed trains, categories of passengers' demand change etc. It is invited that this will be more related to structure of delayed trains as well. For that reason, possibilities to define structure of delayed trains are followed in the model. Simulation is equipped by an exhaustive-search algorithm evaluating all possible values of delay by selected set of trains as well for this purpose.

Passengers' selection of train to use is improved by an algorithm comparing candidate trains not only by departure times in station of boarding, but also by arrival times to the station of alighting. The necessity of this is caused by the fact that model is designed for comparison of trains using different railway lines between the origin and destination as well. The model is able to work in partial network point of view as well. On the other hand, model does not reflect any condition related to vehicle and staff circulations. Possible delay of each train is generated independently according to defined conditions (valid for this discrete random variables).

The model was created in Microsoft Excel using tables of inputs and outputs. The main part of the model is based on set of macros created in Visual Basic for Applications (VBA). The length of the programme code is more than 2,000 lines.

\section{Problem definition}

The first input to be entered is the data on the line or operational section (part of the network). The calculations consider each transport direction (direction of travel) separately. This data is entered using the 
names of railway stations or stops to be included in the future solution. At the same time, it is possible to reduce the number of stops by replacing a homogeneous section, in which all the stations are of similar type, with one stop combining all the stops within the section. This results in a simplification which needs to be approached carefully. It is recommended to enter selected stations or stops representing train journeys and transport demand beyond the area in question. This allows for examining the total number of passengers.

Another key input is the information on the individual trains in question, the stations and stops they serve and their timetable (arrivals/departures to/from these stations). Technically, this involves indicating the train (entering the number or name, or their combination) and the respective arrivals and departures.

The third input is the data on passenger capacity of the individual train units. For simplicity, the same capacity is considered within the entire section. Naturally, it is possible to enter different passenger capacities for different trains in accordance with the (planned) unit structure.

\section{Railway traffic simulation}

As mentioned above, the simulation of railway traffic (specific train journeys) is approached macroscopically. The aim is to establish a collection of specific values of arrivals and departures of the respective trains to/from the individual stations.

As for stochastic modelling of these train journeys, the same approach is used as in model [10]. Delays (or early arrivals) are approached as a discrete random variable with a precision of 1 minute. The (continuous) variable is discretized to facilitate the distribution of probability of delay using the specific values of delay probability. From a substantive point of view, this distinguishing level is acceptable. Setting parameters of continuous distribution of probability of a random variable would often involve variations and would entail a more complex approach. For a discrete variable, the delay statistics is sufficient with a relatively easy statistical evaluation (establishing the probability).

Furthermore, it is possible to create a set of conditions representing the correlations between arrivals and departures and modelling e.g. the waiting for delayed trains or basic technical-technological relations (e.g. the need to wait for an oncoming train on a singletrack line).

On the other hand, if there is a more detailed microsimulation model of railway traffic already available, it is possible to draw on it and adopt its results. In this case, it is necessary to take over the collection of modelled ("real") values of arrivals and departures of individual trains to/from the stations. Only the part of the model presented herein will then be used which deals with the allocation of passengers to individual trains.

\section{Railway traffic simulation}

When monitoring the use of trains by passengers, it is also necessary to model the way they accumulate at stations in regards to the possibility to use an earlier train, or a train leaving earlier in case of a delay.

Moreover, as already mentioned, not all passengers have the same possibilities or willingness to use them. The train leaving earlier in the case of a delay doesn't need to be a suitable alternative for all passengers originally waiting for the delayed train.

For these reasons and to ensure the most faithful modelling of the above mentioned factors, a microscopic approach is taken. Transport demand is classified in the model according to the intended (demanded) train and the demanded transport relation.

On the other hand, specific transport demand, intensities of passenger transport flows and way of accumulation are applied for theoretical evaluation of train cancellation. It is inspired by real situation. For instance, uniform way of passengers' accumulation confirmed for short headway times by rapid transport surveys made by authors' department [7]; weaker transport flows originating in smaller stations than in rush hubs etc. On the other hand, all of these features were adapted to purposes of theoretical research and they are not related to any real train service.

The transport relations are classified according to the stations and stops served (by the originally demanded train). For simplicity, where the passenger intends to change trains, the interchange station is considered as a final one.

For modelling the passenger accumulation, a similar approach is taken as in the case of delay: time discretization with a precision of one minute. It is assumed that passengers arrive deterministically in accordance with the planned timetable/departure, regardless of a potential delay. It is possible to enter the manner of accumulation, i.e. the time period, in which the passengers accumulate, and the nature of this accumulation (e.g. continuous, batch).

The final train choice of passengers is modelled using four key conditions:

a. the "replacement" train must serve the final (interchange) station or stop,

b. "replacement" train is selected between all trains departing in defined time period $(7 \mathrm{~min}$ period is applied) according to the first arrival (e.g. passengers can wait on a faster train departing later, but arriving earlier),

c. for transfer between individual trains, a probability matrix is created for the choice of this train as a replacement train (depending on the intended and replacement trains), passenger flow can be divided between individual trains according to defined probabilities,

d. additional conditions need to be met, e.g. that it is expected for the replacement train to reach the final (interchange) station earlier than the originally intended train (taking into account its delay).

Condition (a) is simplifying to a certain extent; for the future, it will be necessary to explore the possibilities 
of including such alternatives, where the passenger changes the final station or makes an indirect journey, to make the model even more accurate. The change to final station can for instance apply to railway centres, where different stations have similar connections to urban public transport, or to the city infrastructure.

As for (c), probabilistic assessment is performed due to the fact that not all passengers are equally willing to use a replacement train. Moreover, the probability is generally not the same for all pairs of trains. As mentioned above, the reason can be the different rates, obligatory seat reservation, etc. In some cases, this option can even be impossible (e.g. in case of trains solely composed of sleeping cars and couchette coaches). The collection of waiting passengers is then distributed between the intended and replacement trains based on this probability.

The (d) conditions can then be added depending on the specific situation in question.

\section{Configuration of model for research of train cancellation}

Model railway network is consisted of 8 stations and 8 line segments interconnecting them. The configuration of this network is in the Fig. 1. Considered transport direction is from east to west (in direction from $\mathrm{A}$ to $\mathrm{C}$ ).

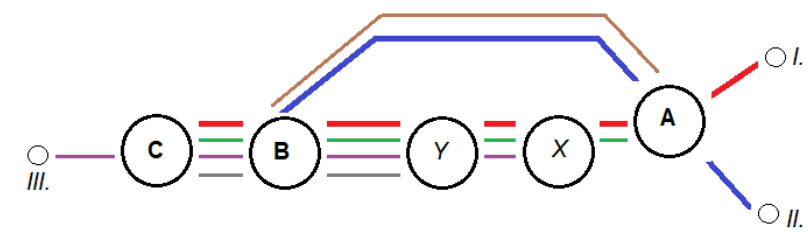

Fig. 1. Model railway network.

The core of transport relations is organized between the stations $\mathrm{A}, \mathrm{B}$ and $\mathrm{C}$. Stations $\mathrm{X}$ and $\mathrm{Y}$ are intermediate stations on the railway line $\mathrm{A}-\mathrm{B}(-\mathrm{C})$. Stations marked as I., II. and III. are stations representing direct leading of trains in outlying areas of primary modelled network between $\mathrm{A}$ and $\mathrm{C}$.

Station A is representing a regional hub station. Station B is a station where 2 railway lines are connected. This station is located e.g. on the border of city area and it can be destination for high number of passengers as well. Station $\mathrm{C}$ is representing the main destination (e.g. the main station in a city).

Red line I. - A - B - C is a line of long-distance fast trains (with no stop at $\mathrm{X}$ and $\mathrm{Y}$ intermediate stations). This line is operated with $60 \mathrm{~min}$ line headway time.

Blue line II. - A $-\mathrm{B}-\mathrm{C}$ is also a line of longdistance fast trains, but using different railway line between $\mathrm{A}$ and $\mathrm{B}$. Headway time on this line is $120 \mathrm{~min}$.

Other lines are regional (suburban). Lines $\mathrm{A}-\mathrm{C}$ (green), X-III. (violet) and $\mathrm{Y}-\mathrm{C}$ (grey) are operated every $30 \mathrm{~min}$. These lines are creating a collective operation between $\mathrm{Y}$ and $\mathrm{C}$ with collective headway of $10 \mathrm{~min}$ between subsequent regional trains.
Regional line A-B (brown) is leaded by alternative railway line. The line is operated with variable headway time of 30 or $60 \mathrm{~min}$. Travel times to regional centre (from station $\mathrm{A}$ to $\mathrm{B}$ or $\mathrm{C}$ ) on this alternative line are longer in comparison with lines using the main line (over $\mathrm{X}$ and $\mathrm{Y}$ ).

The model is consisted of 42 trains representing morning and forenoon operation. The length of modelled time period is 6 hours.

\section{Parts of network}

Each part of the railway network in model represents different aspects of railway public passenger transport.

Station A is representing selection between different kinds of trains (long-distance fast or regional trains) as well as substitution effects of alternative railway line for lines going over X and Y. Network approach is applied.

Stations $\mathrm{X}$ and $\mathrm{Y}$ represent situation of selection between regional trains of similar type using the same railway line.

Railway line segment $\mathrm{Y}-\mathrm{C}$ is a segment with rush operation of regional lines comparable with urban public transport (like tram transport) in short headway of 10 min.

Segment to the station III. represents a limitation for passengers travelling behind the station C. For instance, passengers from Y travelling to III. can't simply change the train in the case of delay and to use synergic effects of this operation. It is modelled as a specific step with the model algorithm.

\section{Principles of evaluation redistribution passengers' demand}

he situation in the field of redistribution of passengers is evaluated by demand of passengers after utilization of each train in given specific conditions (in competition of other trains possibly going to the same destination). The base for comparison is created by passengers' demand after using of the train in the case of operation with according to time schedule (in time).

Following categories are defined for easier possibility to evaluate changes in demand in comparison with operation according to time schedule (in time):

- Increase - passenger number in specific replication is higher.

- Stagnation - the same number like in the case of operation according to time schedule.

- Small decrease - demand in specific replication is decreased by less than $30 \%$.

- Medium decrease - demand in specific replication is decreased by $30-50 \%$.

- Important decrease - demand in specific replication is decreased by more than $50 \%$. 


\section{Discussion of results}

Simulation was realized according 3 different scenarios for possibility to reach more general results. On the other hand, the results of simulation always have particular character in mathematical point of view as it was stated above.

\subsection{Scenario 1 - Small and frequently occurred operational delays}

This scenario is inspired by a common (normal) operation. Each train has individually simulated delay as integer value from 0 to 9 minutes. These delays are simulated according to probability distribution displayed by the Fig. 2 .

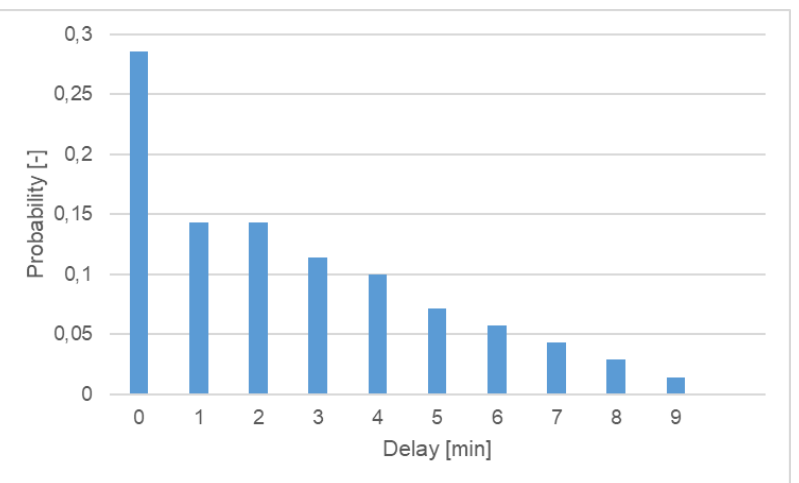

Fig. 2. Scenario 1 - discrete distribution of probability of delays.

Average percentage of delayed trains is $71.02 \%$. Minimum number of delayed trains is 20 , maximum is 38 from all 42 simulated trains. Average delay (of all trains) is $2.50 \mathrm{~min}$ and average delay of delayed train is $3.52 \mathrm{~min}$. These values are related to 500 simulated replications.

Average results characterizing redistribution of passengers for 500 simulated replications are summarized in the Tab. 1.

Table 1. Scenario 1 - Redistribution of passengers.

\begin{tabular}{|c|c|c|c|c|c|}
\hline \multirow{2}{*}{ 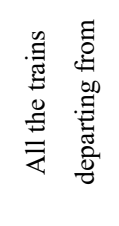 } & \multirow{2}{*}{ 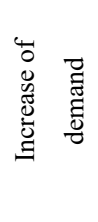 } & \multirow{2}{*}{ 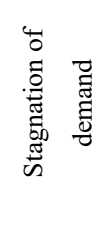 } & \multicolumn{3}{|c|}{ Decrease of demand } \\
\hline & & & $\begin{array}{l}\overline{\text { ज्ञ }} \\
\text { फ }\end{array}$ & $\begin{array}{l}\text { 咅 } \\
\stackrel{0}{\Sigma}\end{array}$ & 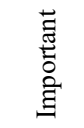 \\
\hline Station A & $38.65 \%$ & $27.48 \%$ & $25.88 \%$ & $1.02 \%$ & $6.97 \%$ \\
\hline Station X & $31.96 \%$ & $36.73 \%$ & $14.47 \%$ & $8.67 \%$ & $8.17 \%$ \\
\hline Station Y & $39.13 \%$ & $21.23 \%$ & $21.54 \%$ & $9.96 \%$ & $8.14 \%$ \\
\hline
\end{tabular}

There is visible in the Tab. 1 that there are some cases of trains, when demand after they can be decreased about more than $50 \%$. These trains can be candidate trains for cancellation. Problem following from more detailed analysis of simulation results, is that the situation is quite different in individual replications. All types of demand change are recorded by the most of trains. Only one train (fast long-distance train from A using longer alternative line) is typically placed in the category of important decrease of demand. On the other hand, this train can't be cancelled due to long-distance character of train.

Train cancellation can be strictly related to operative control of transport. It can't be prepared in a "systematic" way - e.g. with possibility to place such notice about this into time schedules, to reflect it by optimization of vehicle circulations etc. With respect to these facts it can be presupposed that train cancellation can be effective by less than $7 \%$ of trains (if all other technological conditions will be fulfilled as well). This number of trains can be lower in practice due to other operational conditions (e.g. circulation of vehicles, necessity to ensure possible interchanges etc.). Mentioned value is estimation of ratio of trains able to be considered in this point of view only.

\subsection{Scenario 2 - Higher and less frequently occurred delays}

The second simulated scenario is focused on the situation of higher, but less frequent delays. Distribution of probability is in Fig. 3. Delays of $0,5,10,15$ and 20 minutes are generated only.

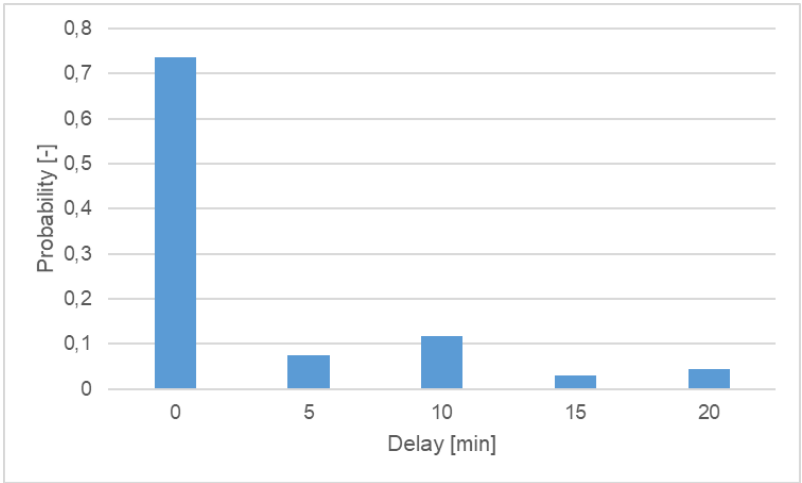

Fig. 3. Scenario 2 - discrete distribution of probability of delays.

Average percentage of delayed trains is $25.85 \%$. Minimum number of delayed trains is 3 , maximum is 21 from all 42 simulated trains. Average delay (of all trains) is $2.80 \mathrm{~min}$ and average delay of delayed train is 10.83 min. These values are related to 500 simulated replications.

The main difference between scenarios 1 and 2 is illustrated by above mentioned values. Result of evaluation of redistribution of passengers mentioned in the Tab. 2 are corresponding. 
Table 2. Scenario 2 - Redistribution of passengers

\begin{tabular}{|c|c|c|c|c|c|}
\hline \multirow{2}{*}{ 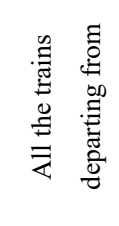 } & \multirow{2}{*}{ 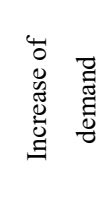 } & \multirow{2}{*}{ 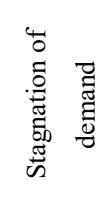 } & \multicolumn{3}{|c|}{ Decrease of demand } \\
\hline & & & $\begin{array}{l}\overline{\bar{\Xi}} \\
\text { है }\end{array}$ & 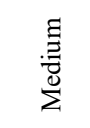 & 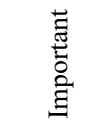 \\
\hline Station A & $32.00 \%$ & $47.60 \%$ & $6.99 \%$ & $2.28 \%$ & $11.13 \%$ \\
\hline Station X & $14.86 \%$ & $70.94 \%$ & $1.33 \%$ & $1.15 \%$ & $11.71 \%$ \\
\hline Station $\mathrm{Y}$ & $20.16 \%$ & $58.97 \%$ & $1.80 \%$ & $3.24 \%$ & $15.82 \%$ \\
\hline
\end{tabular}

Dominant result of this scenario 2 is that there is stagnation of passengers' demand by most of trains. It is related to the fact that the most of trains was operated in time. Increased length of delay caused increased ratio of trains in category with important decrease of demand. Only one train (regional train from A to B using longer alternative line out of $\mathrm{X}$ and $\mathrm{Y}$ ) is typically placed in this category. All other trains are located in categories of increase or stagnation. It means that it is not possible to select a set of trains candidate for possible cancellation. Decrease of demand can be occurred randomly. It must take a part of operational control of railway transport as well.

\subsection{Scenario 3 - Relation to value of delay}

The last scenario is quite different. It is dedicated to research of relation between the value of delay and passengers' demand after train.

The most of trains is operated according to time schedule (in time) in this scenario. The trains of regional line $\mathrm{A}-\mathrm{X}-\mathrm{Y}-\mathrm{B}-\mathrm{C}$ are influenced by delay only. Impact of this delay on passengers' demand after one selected train of this line is evaluated. Exhaustive search algorithm is applied. All integer values of delay from interval $\langle 1,60\rangle$ minutes are applied, simulated and evaluated. The results are in the Fig. 4.

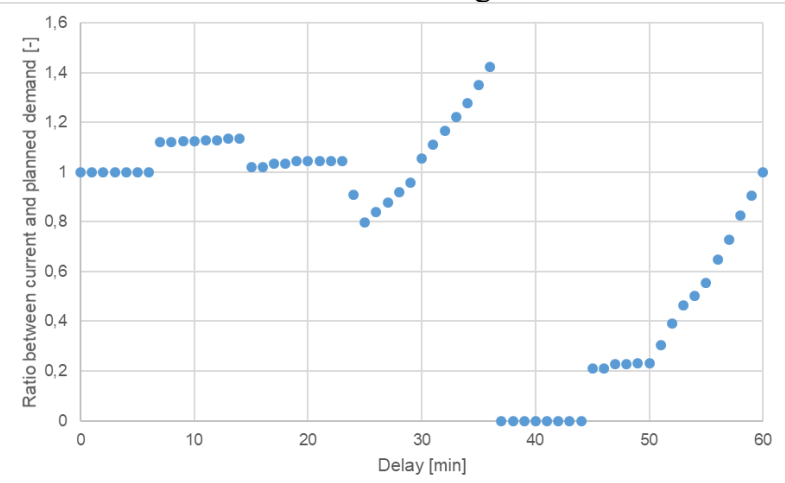

Fig. 4. Scenario 3 - relation between value of delay and ratio of current and planned demand

Planned demand represents demand considered for a situation when considered regional train from $\mathrm{A}$ to $\mathrm{C}$ is operated according to time schedule (in time). Current demand represents demand identified by simulation model for given (considered) value of delay.
It can be seen in the Fig. 4 that this relation is influenced by departures (from station A) of other trains operated on the same relation. It is possible to be seen that delay can have positive as well as negative impact on demand. As it follows from Fig. 4 it is relative effective to operate this train when the delay is lower than $37 \mathrm{~min}$ or higher than $50 \mathrm{~min}$ (if the planned occupation is used by $50 \%$ or more). When the train will be delayed about $37-49$ min, train cancellation can be considered as the possibility how to save the capacity of railway infrastructure (line). This decision is strictly related to specific (given) operating conditions (time schedule), Fig. 4 will be different for each specific situation.

\section{Conclusion}

It is declared by the research results that application of simulation models in the field of interface between railway infrastructure capacity and transport demand after individual trains is possible.

Train cancellation is not a simply tool. Its application and effectiveness is related to complex of operational conditions and time schedule, not only to capacity occupation rate of give railway line. A lot of questions based on results mentioned in this paper can take a part of future research.

The work was supported from ERDF/ESF "Project PosiTrans - University of Pardubice cooperation and application sphere in application oriented research of localization, detection and simulation systems for transport processes" (No. CZ.02.1.01/0.0/0.0/17_049/0008394).

\section{References}

1. Codex UIC 406 - Capacity. 1st ed. Paris: UIC International Union of Railways, 2004

2. J. BULÍČEK, Nová železnični technika: nové železniční trendy, 25, 2 28-31 (2017)

3. L.W. JENSEN L.W. et al., Transportation Research Part C 74, 126-149, (2017) http://dx.doi.org/10.1016/j.trc.2016.10.013

4. R.M. LUSBY et al., European Journal of Operational Research http://dx.doi.org/10.1016/j.ejor.2017.07.044

5. J.W. ANDERSON et al., Journal of Rail Transport Planning \& Management 3 95-110, (2013), http://dx.doi.org/10.1016/j.jrtpm.2013.12.002

6. J. LIANG, et al. Journal of Rail Transport Planning \& Management (2017), http://dx.doi.org/10.1016/j.jrtpm.2017.08.002

7. J. BULÍČEK, V. MOJŽÍŠ, et al. Modelování technologických procesù $v$ dopravě. Pardubice: Univerzita Pardubice, , 223 pp. (2011)

8. A. ČERNÁ, - J. ČERNÝ, Manažerské rozhodováni o dopravních systémech., 230 pp. (2014) 
9. J. GAŠPARÍK, J. KOLÁŘ, Železnični doprava technologie, ř́zení, grafikony a dalšich 100 zajimavostí., 432 (2017)

10. J. BULÍČEK, Vědecko-technický sborník ČD No. 40 (2015). [online], https://vts.cd.cz/documents/51448/51619/4015.pdf/ 